\title{
COMPOSTING OF ORGANIC MATTER. MICROBIOLOGICAL ASPECTS
}

\section{V. Gatsenko}

One of the main ways to increase the humus content in soils is the use of organic fertilizers. However, recent decline of livestock development limits the application of organic fertilizers in full. But along with traditional types of fertilizers such a direction as biocomposting of organic matter of different origin actively develops.

For a long time the composting of organic matter was carried out uncontrollably, without taking into consideration the features of biochemical and microbiological processes. the period of the study of methods of manure storage, which is mediated composting, can be considered the beginning of composting research. First of all, these are works by M. Korsakov and V. Bylinkina (1935), which present the results of research of agronomic indicators, as well as data on the manure microbiota. The authors concluded that the quality of manure is affected by the way it is stored and nutrient losses are directly related to the presence of microorganisms.

An important step in cognition of the features of composting are research works of V. Afanasiev and V. Miller, resulting in the establishment of interrelation between thermogenesis and physical and chemical characteristics and the dynamics of organic matter decomposition and critical moisture content of compost was determined as one of the main conditions for effective composting [3].

In $80-90$-s of the previous century Ye. Mishustin and I. Arkhypchenko studied in details another aspect of composting aeration. It was found that the flow of air to the compost provides active development of microbiota. Thus, at optimum aeration it was detected the growth of microorganisms number involved in the transformation of mineral nitrogen compounds, including nitrifying. Also, these scientists developed and improved technological solutions for binding nitrogen with peat in compost $[1 ; 2$; 31].

The conducted research reveals that composting is a dynamic microbiological process that occurs through the activity of microorganisms of different groups: bacteria, actinomycetes, fungi, yeasts and others. The study of the population of bacteria, fungi and actinomycetes involved in composting was held by a number of researchers. It was found that the dominant form of microorganisms is mesophiles. Up to $90 \%$ of their number belongs to bacilli, chromogenic bacteria and oligotrophs $[24 ; 46]$. At the beginning of composting aerobic bacteria predominate; in the following stages the number of bacteria reduces [22].

Today the issue of organic matter composting has a dynamic and multi-vector character of development. The prospect of biological composting is to study and take into account the microbiological aspects which can provide process control and create conditions for the dominance of introduced microorganisms. The consideration both agrochemical indicators and microbiological characteristics of the processes will allow to change mechanistic approaches to composting for scientifically based ones and create the range of bioorganic fertilizers and biological products that will have different functional direction. In particular, the creation of composts with high content of phytohormones, soluble phosphorus compounds is possible, or those, enriched with fungi-antagonists of specific pathogens of crops and others. 